\title{
HISTÓRIAS MAL CONTADAS; A CANÇÃO DOS VELHOS CAÇADORES E HABITAR O SOM: RETRATO FALADO DA LEITURA EM VOZ ALTA
}

\author{
Maria Edith Romano Siems ${ }^{\mathrm{i}}$
}

CASTRO, Rodolfo. Histórias mal contadas: nueve cuentos mal contados. Lisboa: Editora Boca, 2018. (Coleção HOT histórias oralmente transmissíveis)

CASTRO, Rodolfo. Habitar o som: retrato falado da leitura em voz alta. [sl.]: Rodolfo Castro, 2019.

CASTRO, Rodolfo. A canção dos velhos caçadores. [sl.]: Rodolfo Castro, 2019a.

Em uma fria manhã brasileira, tomei contato, pela primeira vez, com um livro de Rodolfo Castro. Tratava-se do Contos da Meia Noite do Mundo, publicado pela editora Aletria, em 2017, que me causou viva impressão, não apenas pelo primoroso trabalho gráfico que constituia a obra, mas pelo teor do texto. Conciso, direto e profundamente ferino na apresentação de contos, em sua origem, recheados de crueldade e de fina acidez no tratamento de temas que envolviam as humaníssimas violência e morte.

Numa dessas voltas que a vida dá, o contato direto com o autor, em sua versão contador de histórias, em Lisboa, em setembro de 2019, recompõe a presença dessas temáticas violência e morte, agora tratadas com charme, graça e elegância, no corpo a corpo de apresentações junto a crianças das mais diversas idades e condições. E aí me deparo com o forte impacto que o tratamento do tema da morte causa aos pais e educadores presentes. Momentos em que é possível sentir as respirações em suspenso e uma tensão prescrutadora no ar, que parece poder ser cortado a faca, enquanto as crianças dialogam, interagem, reagem e participam ativa e naturalmente da sequência dos contos.

Deste contato com o autor, amplia-se o acesso a suas obras e emerge um sentido de responsabilidade de oferecer a possibilidade a outros educadores, de conhecerem o trabalho de Rodolfo Castro e a rica oportunidade de reflexões sobre a vida em suas diferentes faces, que sua produção literária nos oferece.

Nosso objetivo nesta resenha é apresentar três obras recentes de Rodolfo Castro, sendo duas delas (CASTRO, 2018 e 2019a) com uma abordagem que as aproxima da Literatura Infantil e uma delas (CASTRO, 2019) em que o ato da leitura em voz alta é analisado em profundidade, como ato formativo e relacional. Em nossas análises, salientamos a forma natural com que as temáticas de finitude e morte transpassam a obra de Rodolfo Castro, constituindose, em nosso entendimento, em excelente material para, entre outras coisas, oportunizar a todos elementos de abordagem e reflexão sobre estas temáticas. 
A questão da morte que, nas sociedades ocidentais temos evitado tocar, em especial no contato com crianças e adolescentes, vem sendo objeto de estudos de autores que trazem para a Filosofia da Educação o tema da Educação para a Morte como Azevedo (2006) e Santos (2011). Octavi Fullat (1982 apud AZEVEDO 2006, p. 169) nos interroga: "Se é tão corrente morrer, porque não ter isto presente ao educar." Azevedo ainda nos alerta que:

O professor está continuamente a falar da morte e da vida. Fala de civilizações que desapareceram para sempre, de ideias que rapidamente obsolesceram, de autores que deixaram uma obra incompleta. Falam de condições de subsistência, de cuidados a ter com uma saúde e um ambiente cada vez menos promotor de vida. A morte, chamada ou não a intervir, tem lugar em todas as salas de aula. Senta-se junto de cada educador. A este, a opção de ignorar a intrusa ou de mostrar o lobo que inexoravelmente devora tanto avozinhas como capuchinhos vermelhos e o próprio caçador. (AZEVEDO, 2006, p. 169)

E aqui, a literatura, em seu vasto universo de alcance nas sociedades humanas, tem um papel fundamental. Da fruição da palavra ao encantamento da imaginação; na dimensão artística que carrega ou no sempre controverso papel que assume como estratégia pedagógica em espaços de educação formal, assume condição privilegiada de trazer ao cotidiano a questão da finitude que nos acompanha ao longo do viver.

Santos (2011, p. 407) ao tratar da concepção de Educação para a Morte, numa reflexão a partir da Pedagogia Crítica, em sua articulação com as bases da Escola de Frankfurt e o pensamento freireano, nos apresenta este tema como "um desafio pedagógico ao qual não nos podemos furtar" e a esta, assim se refere:

Uma educação sobre a morte é, assim, uma das tarefas a ser cumprida por um projeto educacional que vise, de facto, a construção de identidades críticas e emancipatórias ao serviço da transformação pessoal e social. Esta tarefa é tanto mais urgente quanto, no quadro dos chamados "direitos emergentes", se discute hoje, pelo menos no mundo ocidental, a legitimidade das directivas antecipadas de tratamento, da eutanásia, do suicídio assistido e dos cuidados paliativos integrais.

Em A canção dos velhos caçadores (CASTRO, 2019), Rodolfo nos é apresentado como alguém que, nascido em 1965, no Uruguai “fez metamorfose no México, voltou à vida em Portugal. Em 1986, diplomou-se como professor do ensino básico. Em 1993 deu os primeiros passos como contador de histórias profissional". Nas sessões de contação e leitura de histórias que protagoniza, Rodolfo se auto-intitula como "o pior contador de histórias do mundo", mas seu trabalho vem transcendendo formatos e suportes, passando pela escrita, narrativa, ilustração e por reflexões partilhadas sobre a leitura em voz alta e sua importância no desenvolvimento 
social e cultural das novas e velhas gerações. Exercícios diversos do fazer que se vivificam na relação com a formação de professores e de contadores de histórias.

Nesta resenha nos reportamos a três de suas mais recentes obras com o objetivo de apontar o caráter multifacetado do autor, visto aqui pelo viés das relações com a dinâmica integral da vida que inclui explícita e inteiramente, a presença da morte, como fio condutor e gerador de sentido da existência.

O já citado Canção dos velhos caçadores traz um texto ácido e enxuto, preciosamente ilustrado pelo próprio autor e traduzido por Janeca de Ornellas, apresentando-se a princípio como um conto rural tradicional. A cada página, texto e ilustração se apresentam como se em um ballet, magistralmente coreografado, deixando ao leitor, a cada passo da narrativa, um sentido de suspense. Uma narrativa cinematograficamente coreografada em suporte bidimensional e, seguindo o que já se apresenta como característica do autor, um desenlace que subverte o esperado nas relações tradicionais de poder que comporiam narrativas dessa matriz.

Em Nove histórias mal contadas/Nueve cuentos mal contados, novamente assistimos ao ballet do texto-ilustração realizados pelo autor que contam com a tradução para o português de Joana Aguiar e um belíssimo projeto gráfico de Pedro Serpa, que nos presenteia ainda com um audio livro em CD. Os nove curtos textos cujas matrizes podem ser encontradas na literatura clássica, nos são recontados por Rodolfo, também em suas versões em Português e Espanhol. Uma obra preciosa, em que as marcas do tempo histórico que nos coube viver, com suas profundas reflexões sobre os sentidos dos empoderamentos, relações com o ambiente e noções de saúde e respeito aos próximos em sua diversidade são, de maneira cirúrgica e incisiva trazidos à tona. Releituras com as marcas do "políticamente correto" que, ao sabor da fina ironia do narrador, se tornam pura fruição.

E, por fim, compondo mais uma faceta de Rodolfo Castro, temos ainda em sua produção recente, o belíssimo Habitar o som. Retrato falado da leitura em voz alta. A edição atual de 2019 é, nas palavras do autor, uma re-escrita de textos anteriormente já produzidos e publicados, mas que ganham uma versão atualizada, acrescida dos processos reflexivos vividos pela experiência cotidiana na contação de histórias pa crianças e adultos e na realização de formações com educadores.

Habitar o Som nos oferece uma reflexão sobre os próprios sentidos da literatura, quando por exemplo, nos diz que:

As pessoas são mais complexas e maravilhosas do que os livros. Os livros só adquirem uma categoria de transcendência quando passam através de um 
leitor; só quando são habitados por um ou múltiplos leitores. (CASTRO, 2019, p. 34)

Mas, para além de analisar fenômenos da literatura e das relações com a leitura, autor e autoria, é sobre sentidos profundos da educação que Rodolfo nos faz refletir quando, por exemplo, sintetiza uma das máximas a nortear os defensores da inclusão escolar de todas as pessoas, sinalizando quão patéticas são as ações educativas que tentam levar a todo um grupo de estudantes, ao mesmo lugar, no mesmo tempo, no sentido de "forçar a marcha de cada um até a equiparar com o restante do grupo, violentando assim o tempo interno que todos temos e necessitamos para alcançar a compreensão e o desenvolvimento" (CASTRO, 2019, p. 42).

Uma fina percepção do desenvolvimento humano que rejeita a homogeneização do saber em que se inscrevem expectativas de tamanho único para diferentes atores, esquecendo que a leitura deva constituir-se em momento de gozo, de integração e de inventividade na afetividade.

E é com as palavras do autor que encerramos esse texto, esperando que ele possa alcançar a perspectiva de difundir não apenas a obra de Rodolfo Castro, mas também de ir além, expandindo-a a outros textos e autores, nos permitindo seguir, como "seres humanos criativos", leitores, retirando do livro aquilo de que precisamos e ao levá-lo conoscos nos demos a possibilidade - autor e leitor - de nos enriquecermos juntos (Castro, 2019 a, p. 40). "É essencial ler para os nossos filhos para que, seja onde for que a vida os leve, tenham lar, linguagem, memória, imaginação e pensamento. Poderão nomear o mundo conhecido e também o desconhecido. São seres humanos criativos" (Castro, 2019, p. 46).

\section{REFERÊNCIAS}

AZEVEDO, Maria da Conceição. Valores culminantes: Educação para a morte/Educação para a vida. Revista Portuguesa de Pedagogia, ano 40 -2, p. 159-183, 2006.

CASTRO, Rodolfo. Contos da meia-noite do mundo. Ilustrações: Alexandre Camanho Tradução: Richard Garrel; Rosana Mont'Alverne. Belo Horizonte: Editora Aletria, 2017.

CASTRO, Rodolfo. Histórias mal contadas - Nueve cuentos mal contados. Lisboa, Editora BOCA - Palavras que alimentam Coleção HOT- Histórias oralmente transmissíveis, 2018.

CASTRO, Rodolfo. Habitar o som. Retrato falado da leitura em voz alta. Lisboa, O habitante (edição de autor), 2019. 
CASTRO, Rodolfo. A canção dos velhos caçadores. Lisboa, O habitante (edição de autor), 2019a.

SANTOS, Laura Ferreira. Pedagogia Crítica, sofrimento e educação sobre a morte. Revista Portuguesa de Pedagogia. Extra-Série, p. 401-409, 2011.

\footnotetext{
${ }^{i}$ Pedagoga, Mestre em Educação pela Universidade Federal de Roraima, Doutora em Educação Especial (Educação do Indivíduo Especial) pela Universidade Federal de São Carlos. Pós-Doutora pelo Instituto de Educação da Universidade de Lisboa. Professora do Centro de Educação da Universidade Federal de Roraima. Universidade Federal de Roraima / UFRR. Roraima - Brasil. ORCID iD http://orcid.org/0000-0001-5527-0065
} 